\title{
Effects of fear conditioning on the subsequent acquisition of an avoidance response
}

BURTON M. SLOTNICK, Columbia University, V'w York, N. Y. 10027

Four groups of rats underwent fear conditioning or control procedures prior to shuttle-box training. The four groups in the first part of the experiment received either inescapable signal-shock pairings, unpaired presentations of signal and shock, signal prescntations only, or signal-shock pairings in which shock could be terminated by escape response. The result of the subsequent avoidance training demonstrated that animals which received the inescapable signal-shock pairings performed significantly better than the other three groups.

According to the two-factor theory of avoidance conditioning (Brush, Brush, \& Solomon, 1955) one would expect that the greater the fear aroused in $S$ by a warning signal, the sooner and the better an avoidance response would be learned. However, in a number of studies (Miller, 1948; Meyer, Cho, \& Wesemann, 1960; Stone, 1960, etc.) a conditioned fear response (freezing) has characterized the behavior of animals which showed poor avoidance conditioning. Furthermore, studies have suggested that deficits in avoidance performance following experimental brain lesions may be attributable to an enhancement of this freeze response (Thomas \& Slotnick, 1962; Thomas et al, 1963; McCleary, 1961).

The present study investigates the effects of a conditioned emotional response on the subsequent learning of a shuttle-box response.

\section{Experimental Design}

\section{METHOD}

Thirty-two, naive, adult, Holtzman male rats were divided into four equal-sized groups. In the first part of the experiment each group was subjected to fear conditioning or a control procedure. In the second part of the experiment all groups were given avoidance training under identical conditions.

Fear Conditioning

The four groups and conditioning procedures in the first part of the experiment were as follows: Group CER received classical fear conditioning by buzzer-shock pairings and was conditioned in $9 \times 9 \times 9$ in. wooden boxes equipped with a grid floor. One adaptation or conditioning trial was given each day. On conditioning days each $S$ was placed in a box for 9 min. At the beginning of the fourth minute the CS (buzzer) was turned on and was terminated 1 min later in temporal contiguity with a brief shock. On days when adaptation trials were given, each $S$ was placed in the box for $9 \mathrm{~min}$ but neither the CS nor UCS was presented.

Group $\mathrm{E}$ was given escape-from-shock training in a runway separated into a 10 in. start-box, a 16 in. runway, and a 10 in. goal-box by two hand-operated guillotine doors. On conditioning days, $S$ was placed in the start-box and at the beginning of the fourth minute, the CS was turned on. One minute later the start-box door was raised simultaneously with the onset of shock. The rat escaped from shock by running to the goal-box where it was allowed to remain for $4 \mathrm{~min}$. On adaptation days, $S$ was confined to the start-box for $9 \mathrm{~min}$ but neither the buzzer nor the shock was presented.

There were two control groups. Group CER-X served as a pseudoconditioning control for effects of shock unassociated with the CS. Treatment of animals in this group was identical with the treatment of Group CER except that the CS and UCS were never paired. On shock-trial days these Ss received shock but no CS. On adaptation-trial days they received the (S but no shock.

Group (' was a non-shocked control group. These Ss were treated similarly to animals in (iroup (ER except that on shock-trial days the $\mathrm{C} S \mathrm{~S}$ was presented, but at no time during Part 1 of the experiment w'ere these rats shocked. Activity Test

In order to obtain an index of the (ER (freezing) resulting from the conditioning treatments, a simple activity test similar to that described by Davitz $\&$ Mason (1955) was devised. The test consisted of placing the $S$ in a $9 \times 18 \times 9$ in. box for ? min. The CS was sounded during the entire second minute of the test. The box had a grid floor which was marked off' in six equal $4 \frac{1}{2} \times 6$ in. regions. The activity score was the number of these floor regions entered by the animal's dye-marked, left hind foot. In order to insure a moderate amount of spontaneous activity in the test situation, all Ss were kept on a $23 \mathrm{~h}$ food deprivation schedule. They were allowed to eat for 10 min after each day's trial in special feeding boxes which were similar to the CER conditioning boxes but were painted a different color. This food deprivation schedule was maintained throughout the experiment.

Rats trained on shock escape in the rumway received variable amounts of shock depending upon their running speed. In order to equalize the amount of shock received by the three shocked groups. each $S$ in the CER and CER-X group was roughly matched on the basis of weight with a rat in the runway escape group. On the days when shock trials were given, Group E was run first. The duration of shock received by each rat in the CER and CER-X group was then made the same as the runway latency of its matched partner.

One adaptation or conditioning trial was given atch day in a predetermined order over a 15 day period. The sequences were as follows: On Days 1, 2, 5, 6. 9, 12, and 13 adaptation trials were given; on Days $4,7,8,10,11$, and 15 conditioning trials were given. On Days 3 and 14 the activity test was given.

The UCS was a $0.6 \mathrm{~mA}$ shock. The same C S was used in both the first and second parts of the experiment. It consisted of a $6 \mathrm{~V}$ door buzzer placed on the table in front of the conditioning apparatus. The intensity of the buzzer was adjusted to a level that did not cause a noticeable startle response in naive animals.

Avoidance Conditioning

On Day 16 all Ss began avoidance training in a modified Miller-Mowrer box. The two compartments of the shuttle-box were each $9 \times 9 \times 9$ in. They were connected by a $6 \times 6$ in. opening located 2 in. above the grid floor. Each compartment was illuminated by a $7.5 \mathrm{~W}$ bulb. Ss were observed from below through tilted mirrors. Thi CS-UCS interval was $10 \mathrm{sec}$; intertrial interval was randomly varied between 50 and 120 sec; the UCS was $0.5 \mathrm{~mA}$ shock through a "grid scrambler." All spontaneous crossings during intertrial intervals were shocked. Fifteen trials a day for a mininum of 60 trials were given. For rats which in the first 60 trials had not reached a criterion of nine avoidances out of 10 consecutive trials during any session. conditioning was continued until the criterion was reached or for a maximum of 150 trials.

\section{RESULTS}

\section{Activity Tests}

In analyzing the activity data, a ratio was computed for each animal that reflected the change in activity from the non-buzzer to the buzzer period for each test. The ratio used 
Table 1

Average Avoidance Conditioning Scores and Associated Ratios

\begin{tabular}{lrrrrrrr}
\hline & \multicolumn{5}{c}{ Groups } & & \\
\cline { 2 - 6 } $\begin{array}{l}\text { Performance } \\
\text { Measures }\end{array}$ & CER & E & CER-X & C & F ratio & p value \\
\hline $\begin{array}{l}\text { Trial of first avoid- } \\
\text { ance response }\end{array}$ & 8.3 & 12.9 & 20.4 & 18.0 & 6.27 & $<.01$ \\
$\begin{array}{l}\text { Number of CARs } \\
\text { in } 60 \text { trials }\end{array}$ & 31.3 & 17.1 & 25.6 & 27.5 & 2.66 & N.S. \\
$\begin{array}{l}\text { Number of CARs } \\
\text { in 30 trials }\end{array}$ & 12.4 & 6.1 & 6.4 & 5.4 & 3.66 & $<.05$ \\
$\begin{array}{l}\text { Number of shocks } \\
\text { to criterion }\end{array}$ & 26.3 & 82.8 & 42.6 & 54.9 & 4.19 & $<.05$ \\
$\begin{array}{l}\text { Number of trials } \\
\text { to criterion }\end{array}$ & 48.5 & 114.9 & 64.0 & 87.9 & 5.40 & $<.01$ \\
\hline
\end{tabular}

was $B-A / B+A$ where $A$ is the activity during the first minute and $B$ the activity during the second (buzzer) minute.

The difference in ratio scores between the two activity tests for each group were compared using the Mann-Whitney U test. This analysis showed a significant decrease in activity during the CS period of the second test only for Groups CER and E ( $p<.001$ and $p<.005$ ). The striking behavioral change observed in Groups CER and E during the buzzer period of the second test consisted of a sudden cessation of activity accompanied by urination and/or defecation at CS onset by every animal of these two groups.

Avoidance Conditioning

Five measures of avoidance conditioning were used in analyzing the performance of the four groups during the second part of the experiment. These were: shocks to criterion, trials to criterion, number of avoidance responses in the first 30 and first 60 trials, and the trial on which the first avoidance response was made, A 1 by 4 analysis of variance was performed for each of these measures and t-tests were used to test for differences between groups on each measure. The results of the analysis are presented in Table 1. Only the number of avoidance responses in sixty trials did not reach statistical significance.

The data analysis (Table 1) clearly indicated the superiority of Group CER in the acquisition and performance of a shuttle-box avoidance response. This group performed significantly better than Group $C$ in all comparisons yielding a significant $F$ ratio and significantly better than Group $E$ in these comparisons except for the trial of the first avoidance response. Group CER showed significantly better avoidance performance than did Group CER-X for the trial of the first avoidance response and the number of avoidance responses in the first 30 trials ( $p=.025$ or better for above t-tests).

\section{DISCUSSION}

It is clear that prior fear conditioning for Group CER facilitated the acquisition of a shuttle-box avoidance response as indicated by a variety of performance measures. This facilitation was most evident early in training but was also reflected in such overall measures of avoidance conditioning as the number of shocks obtained and number of trials required to reach a performance criterion. In contrast, the escape-conditioned group (Group E) showed poor avoidance conditioning. Whether this poor CAR performance was due to the fact that the escape response in the first part of the experiment was imperfectly learned, to the instrumental conditioning procedure itself or to other factors, is not known. In any case, the marked difference in shuttle-box conditioning between these two groups, both of which showed a strong, well discriminated freeze response to the CS during the stcond activity test, indicates that the antecedents of this freeze response and not the response itself are the important factors in its subsequent effects on the acquisition of an avoidance response.

The fact that Group CER-X performed somewhat better than the nonshocked control group and about as well as Group CER for some measures suggests that effects of inescapable shock alone may account for part of the superior performance of Group CER. Baron, Brookshire, \& Littman (1957) have previously found that prior shock experience aided animals in later avoidance conditioning. The results of Group CER-X in the present study supports their suggestion that prior experience with shock (at least with inescapable shock) is beneficial to later performance where shock is used as an UCS.

Because animals differed widely on the activity scores during the first activity test, an attempt was made to determine if group differences could be accounted for in terms of their initial activity level. Spearman rank-order correlations were run for each group between total activity scores of the first test and two measures of avoidance conditioning: the number of trials to criterion and the number of avoidance responses in 60 trials. The resulting correlations were all insignificant and ranged from -.08 to +.30 . Similarly, no relation was found between the number of seconds of shock received in Part 1 of the experiment and shuttle-box performance.

The fact that shuttle-box avoidance conditioning is enhanced following classical fear conditioning supports the two-factor theory of avoidance conditioning cited earlier and suggests that response inhibition due to freezing may not be an adequate explanation for instances of poor avoidance conditioning as implied by G. Thomas \& Slotnick (1962), Denny \& J. Thomas (1960), and others.

\section{REFERENCES}

BARON, A., BROOKSHIRE, K. H., \& LITTMAN, R. A. Effects of infantile and adult shock-trauma upon learning in the adult white rat. Journal of Comparative \& Physiological Psychology, 1957, 50, 530-534.

BRUSH, F. R., BRUSH, E. S., \& SOLOMON, R. L. Traumatic avoidance learning: The effects of CS-US interval with a delayed-conditioning procedure. Journal of Comparative \& Physiological Psychology, 1955, $48,285-293$.

DAVITZ, J. R., \& MASON, D. J. Socially facilitated reduction of a fear response in rats. Journal of Comparative \& Physiological Psychology, $1955,48,149-151$.

DENNY, M. R., \& THOMAS, J. O. Avoidance learning and relearning as a function of shuttle box dimensions. Science, 1960, 132, 620-621.

MILLER, N. E. Studies of fear as an acquirable drive: I. Fear as motivation and fear reduction as reinforcement in the learning of new responses. Journal of Experimental Psychology, 1948, 38, 89-101.

McCLEARY, R. A. Response specificity in the behavioral effects of limbic system lesions in the cat. Journal of Comparative \& Physiological Psychology, 1961, 54, 605-613.

MEYER, D. R., CHO, C., \& WESEMANN, A. F. On problems of conditioned discriminated lever-press avoidance response. Psychological Review, 1960, 67, 224-228.

STONE, G. Effects of some centrally acting drugs upon learning of escape and avoidance habits. Journal of Comparative \& Physiological Psychology, 1960, 53, 33-37.

THOMAS, G. J., FRY, W. J., FRY, F. J., SLOTNICK, B. M., \& KRIECKHAUS, E. E. Behavioral effects of mammillothalamic tractotomy in cats. Journal of Neurophysiology, 1963, 26, 857-876.

THOMAS, G. J., \& SLOTNICK, B. Effects of lesions in the cingulum of maze learning and avoidance conditioning in the rat. Journal of Comparative \& Physiological Psychology, 1962, 55, 1085-1091. NOTE

1. This study was supported by Research Grant M-1370 from the National Institute of Mental Health, USPHS to G. J. Thomas. The author gratefully acknowledges the assistance and encouragement of G. J. Thomas during the course of this study. 